clinical practice in the management of patients with severe COPD and persistent hypercapnia.

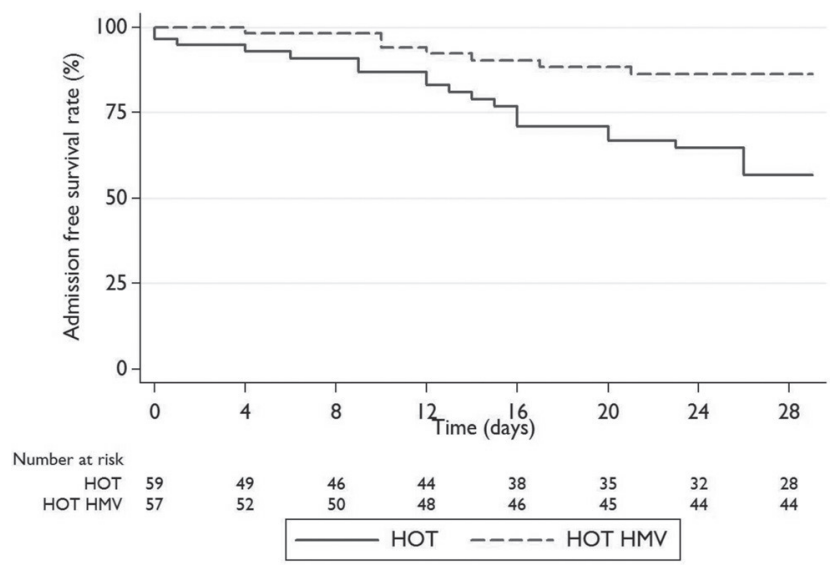

Abstract S115 Figure 1 Time to hospital re-admission by treatment arm

\section{S116 HOT DECAF: A RCT COMPARING HOME TREATMENT AND INPATIENT CARE IN COPD EXACERBATIONS SELECTED BY LOW RISK DECAF SCORE}

${ }^{1} \mathrm{C}$ Echevarria, ${ }^{1} \mathrm{~T}$ Hartley, ${ }^{2} \mathrm{~J}$ Gray, ${ }^{3} \mathrm{C}$ Muirhead, ${ }^{4} \mathrm{~A}$ Van-Wersch, ${ }^{1} \mathrm{f}$ Miller, ${ }^{1} \mathrm{~J}$ Steer, ${ }^{3}$ AJ Simpson, ${ }^{3} \mathrm{GJ}$ Gibson, ${ }^{1} \mathrm{SC}$ Bourke. ${ }^{1}$ North Tyneside General Hospital, UK, Newcastle; ${ }^{2}$ Northumbria University, Newcastle upon Tyne, UK; ${ }^{3}$ Newcastle University, Newcastle upon Tyne, UK; ${ }^{4}$ Teesside University, Teesside, UK

\subsection{6/thoraxjnl-2016-209333.122}

Background The DECAF score is a robust predictor of early mortality in patients admitted with an acute exacerbation of COPD (AECOPD), ${ }^{1}$ and should be routinely documented on admission. ${ }^{2}$ Of importance, $45-53 \%$ of admitted patients are low risk by DECAF (0-1), therefore potentially suitable for hospital at home (HAH). Compared to existing criteria, selection by DECAF would allow inclusion of substantially more patients, some with higher medical dependency.

Methods In a randomised controlled trial (RfPB PB-PG-021330105), patients admitted with an AECOPD were allocated to HAH or usual care (UC). Readmissions for AECOPD within 90 days were managed according to the allocated arm, provided they were low risk (DECAF $=0-1)$. Eligibility criteria included: primary diagnosis AECOPD, DECAF score $0-1$, age 35 or more, 10 or more cigarette pack-year history and obstructive spirometry (FEV1/VC less than 70\%). Total bed days and readmissions over 90 days, and 14 and 90 day mortality were captured. At day 14, patients were asked for their preferred place of care during future exacerbations of similar severity.

\begin{tabular}{lll} 
Abstract S116 Table 1 & Outcome by allocated group & \\
\hline Outcome & UC & HAH \\
& $\mathrm{n}=\mathbf{5 8}$ & $\mathrm{n}=60$ \\
\hline Bed days, $\mathrm{n}$ (IQR) & $5(2-12)$ & $1(1-7)$ \\
Readmission $^{*} \dagger$ & $23(39.7 \%)$ & $22(36.7 \%)$ \\
14 day mortality & 0 & 0 \\
90 day mortality & $1(1.7 \%)$ & $1(1.6 \%)$ \\
Preference for HAH & $51 / 57$ & $54 / 60$ \\
\hline
\end{tabular}

${ }^{*}$ All cause. $†$ One or more readmissions.
Results Between June 2014 to January 2016118 of 207 eligible patients were randomised: female $=56 / 118$ (52.5\%), mean age $(\mathrm{SD})=69.8(10.2)$, mean FEV1\% predicted $(\mathrm{SD})=43.9(17.6)$ and coexistent pneumonia $=24 / 118(20.3 \%)$.

At 14 days, 105/117 (90\%) patients expressed a preference for HAH. Median bed days were 4 days lower in the HAH arm $(\mathrm{p}=0.001)$, with no difference in mortality or readmissions.

Conclusions Selection for HAH by low risk DECAF score is safe, clinically effective, preferred by most patients, reduces total bed days and is a suitable option for up to $50 \%$ of admitted patients.

\section{REFERENCES}

1 Steer J, et al. The DECAF Score: predicting hospital mortality in exacerbations of chronic obstructive pulmonary disease. Thorax 2012;67(11):970-6.

2 BTS national audit report 2015.

\section{Occupational Lung Disease}

\section{S117 WORK-RELATED SYMPTOMS IN LABORATORY ANIMAL WORKERS}

${ }^{1} \mathrm{~J}$ Feary, ${ }^{1 \mathrm{~J}}$ Canizales, ${ }^{1} \mathrm{C}$ Fitzgerald, ${ }^{1} \mathrm{~B}$ Fitzgerald, ${ }^{1} \mathrm{~S}$ Schofield, ${ }^{2} \mathrm{M}$ Jones, ${ }^{2} \mathrm{P}$ Cullinan. ${ }^{1}$ Royal Brompton and Harefield NHS Foundation Trust, London, UK; ${ }^{2}$ Imperial College, London, UK

\subsection{6/thoraxjnl-2016-209333.123}

Introduction Laboratory animal workers frequently report ocular, nasal and respiratory symptoms which occur in the workplace and improve away from work. A proportion of these will be sensitised to animal proteins on the basis of skin prick tests (SPTs) or serum specific IgE testing and will have laboratory animal allergy. The remainder will have work-related symptoms due to other (unknown) causes.

Methods We performed a cross-sectional study (SPIRAL (Safe Practice In Reducing Allery in Laboratories)) of laboratory animal workers exposed to mice across six UK research institutions. Participants completed a self-administered questionnaire, which included detailed questions about symptoms, and underwent SPT to common aeroallergens and mouse epithelium, and specific IgE testing to mouse proteins (epithelium and urine). Those participants reporting ocular, nasal or respiratory symptoms which were worse at work were compared with those with no association between their symptoms and work.

Results 685 laboratory workers were recruited (response rate $88 \%) .187$ (28\%) reported at least one symptom and of these, $45 \%(\mathrm{n}=85)$ were work-related (WR). 56/105 (53\%) reported work-related conjunctivitis; 67/156 (43\%) reported WR nasal symptoms and 22/44 (50\%) reported WR respiratory symptoms. There were no differences between the two groups in sex, smoking status, atopy to a common aeroallergen or job title. Those with at least one WR symptom were significantly more likely to be sensitisied to mouse proteins $(32(37.7 \%)$ vs $10(9.8 \%)$ p $<0.001$ (Table). WR symptoms were significantly more common in those working with mice housed in open cages compared with those housed in Individual Ventilated Cages (IVCs) Prevalence of sensitisation to a common aeroallergen was similar in both groups.

Conclusion In this large study population, prevalence of WR symptoms is reasonably high in all laboratory animal workers and is attributable to mouse allergy in around 50\% of cases, consistent with other previous studies. Symptoms are less prominent in people working with IVCs compared with conventional open cages. Exposure to airborne endotoxin may be a cause for nasal and respiratory symptoms on exposure to mice in non-mouse 


\begin{tabular}{|l|c|c|c|}
\hline Variable & \multicolumn{2}{|c|}{$\begin{array}{c}\text { At least one of ocular, nasal or } \\
\text { respiratory symptoms }\end{array}$} & \\
\hline & Work related & Not work related & p value \\
\hline $\mathrm{N}$ & 85 & 102 & \\
\hline Age in years, median (range) & $31.4(24.6-60.7)$ & $33.4(22.8-57.2)$ & 0.589 \\
\hline Male & $47(55.3)$ & $51(50.0)$ & 0.470 \\
\hline Ever smoked & $27(31.8)$ & $43(42.2)$ & 0.144 \\
\hline Atopic to common aeroallergen & $33(38.8)$ & $41(40.6)$ & 0.806 \\
\hline Sensitised to mouse proteins & $32(37.7)$ & $10(9.8)$ & $<0.001$ \\
\hline OH mouse allergy & $21(24.7)$ & $0(0.0)$ & $<0.001$ \\
\hline Job title & $20(23.5)$ & $29(28.4)$ & \\
& $58(68.2)$ & $64(62.8)$ & 0.720 \\
& $7(8.2)$ & $9(8.8)$ & \\
\hline
\end{tabular}

Abstract S117 Table 1

sensitised animal workers. Measurement of exposure to endotoxin levels in these workers is in progress.

\section{S118 CAN FRACTIONAL EXHALED NITRIC OXIDE HELP PREDICT ASTHMA IN BRITISH FOUNDRY WORKERS?}

${ }^{1}$ RE Wiggans, 'E Robinson, ${ }^{1} \mathrm{~J}$ Sumner, ${ }^{1} \mathrm{~A}$ Codling, ${ }^{2} \mathrm{~L}$ Lewis, ${ }^{1} \mathrm{CM}$ Barber. ${ }^{1}$ Health and Safety Laboratory, Buxton, UK; ${ }^{2}$ Northern General Hospital, Sheffield, UK

10.1136/thoraxjn-2016-209333.124

Background Foundry work may involve exposure to respiratory sensitisers and irritants. There is limited evidence for the use of $\mathrm{FE}_{\mathrm{NO}}$ in occupational settings, and particularly in foundries.

Aim To examine the usefulness of $\mathrm{FE}_{\mathrm{NO}}$ in identifying foundry workers at risk of asthma.

Methods Foundry workers undertook a respiratory questionnaire. Spirometry (Ndd Easy on-PC Spirometer, Zurich) and $\mathrm{FE}_{\mathrm{NO}}$ (NOBreath, Bedfont Scientific, Kent) were measured to ATS/ERS standards. The ATS upper limit of normal (ULN) of 50 parts per billion (ppb), or 45.9ppb for current smokers, determined the high $\mathrm{FE}_{\mathrm{NO}}$ category $\left(\mathrm{FE}_{\mathrm{NO}}>\mathrm{ULN}\right)$. Workers with $\mathrm{FE}_{\mathrm{NO}}>\mathrm{ULN}$ were compared with those with at least one workrelated respiratory symptom (WRRS) and those with obstructive lung function $\left(\mathrm{FEV}_{1} / \mathrm{FVC}<0.7\right)$ using Chi Square and Fisher's Exact Tests.

Results 351 workers (350 men, 99\%) participated. 350 workers had a valid $\mathrm{FE}_{\mathrm{NO}}$ performed. Arithmetic mean $\mathrm{FE}_{\mathrm{NO}}$ was 30.2ppb (95\% CI: 27.3-33.2); geometric mean (GM) $\mathrm{FE}_{\mathrm{NO}} 20.8$ (18.9-22.9) ppb.

$\mathrm{FE}_{\mathrm{NO}}$ exceeded the ULN in $61(17 \%)$ workers. Average age for the $\mathrm{FE}_{\mathrm{NO}}>\mathrm{ULN}$ group was 41.5 (95\% CI: 38.3-44.7), with a mean of $15.8(12.4-19.2)$ years working in the foundry industry.

Workers in the $\mathrm{FE}_{\mathrm{NO}}>\mathrm{ULN}$ group were significantly more likely to have a current diagnosis of asthma $(12 \%$ vs $5 \%$, $\mathrm{p}<0.05)$, have ever suffered allergies (55\% vs 31\%, p < 0.01), or report work-related shortness of breath $(3 \%$ vs $0 \%$, $\mathrm{p}<0.05)$.
Fourteen workers (4\%) had a $\mathrm{FE}_{\mathrm{NO}}>\mathrm{ULN}$ and WRRS (Figure1). Of these 14, only 2 (14\%) had a current diagnosis of asthma (Fisher's $\mathrm{p}=0.20)$. Eight $(2 \%)$ workers had a $\mathrm{FE}_{\mathrm{NO}}>$ $\mathrm{ULN}$ and $\mathrm{FEV}_{1} / \mathrm{FVC}<0.7$, though only $2(25 \%)$ had a current asthma diagnosis (Fisher's $\mathrm{p}=0.08$ ).

Conclusion A significant proportion of foundry workers have $\mathrm{FE}_{\mathrm{NO}}$ levels that exceed the ATS cut point for likely eosinophilic airway inflammation. Of these workers, most had a raised $\mathrm{FE}_{\mathrm{NO}}$ but no WRRS or obstructive lung disease. Only a minority of workers with $\mathrm{FE}_{\mathrm{NO}}>\mathrm{ULN}$ and either WRRS or obstruction had a current diagnosis of asthma. $\mathrm{FE}_{\mathrm{NO}}$ may be useful in identifying foundry workers at risk of asthma and warrants further study.

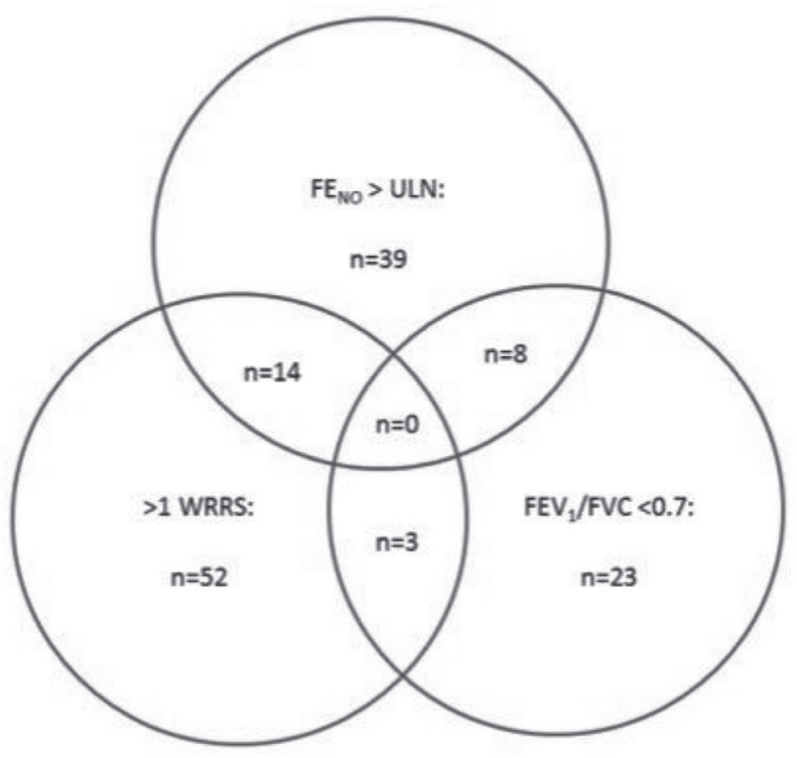

Abstract S118 Figure 1 Overlap between $\mathrm{FE}_{\mathrm{NO}}>\mathrm{ULN}$, work-related respiratory symptoms and obstructive spirometry in foundry workers. Total numbers in each group (\%of total): $\mathrm{FE}_{\mathrm{NO}}>\mathrm{ULN}$ : $\mathrm{n}=61(17 \%)_{i}>1$ WRRS: $\mathrm{n}=69(20 \%) ; \mathrm{FEV}_{1} / \mathrm{FVC}<0.7=\mathrm{n}=34(10 \%)$. $\mathrm{FE}_{\mathrm{NO}}>\mathrm{ULN}=$ $\mathrm{FE}_{\mathrm{NO}}$ above $50 \mathrm{ppb}$ or $45.9 \mathrm{ppb}$ in current smokers; WRRS = at least one work-related respiratory symptom 